\title{
PERANCANGAN BUKU FOTOGRAFI WISATA KARST DI KABUPATEN MAROS SULAWESI SELATAN
}

\author{
Farhan Fachriansyah' ${ }^{1}$, Yanuar Rahman ${ }^{2}$ \\ 1,2Universitas Telkom
}

Received: 25 September 2017

Revised: 22 Februari 2018

Available online at: bit.do/demandia

\begin{abstract}
Abstrak: Kabupaten Maros di Provinsi Sulawesi Selatan memiliki banyak wisata alam yang menarik dengan nilai sejarah. Berdasarkan potensi itu, Dinas Budaya dan Pariwisata Kabupaten Maros membuat program bernama Wisata Pendidikan. Program ini berisi kegiatan rekreasi alam sekaligus pendidikan mengenai pengetahuan alam dan sejarah yang terdapat pada tiga wisata karst, yaitu Rammang-Rammang, Leang-Leang, dan Bantimurung. Pihak Dinas sudah melakukan beberapa promosi mengenai program ini, salah satunya melalui media buku fotografi. Namun setelah mengalami proses evaluasi, lingkup pembahasan buku ini terlalu luas sedangkan paparan informasi mengenai wisatanya tidak mendetail serta dinilai memiliki beberapa masalah dari segi estetika desain dan konten. Berdasarkan informasi di atas, dibutuhkan sebuah media buku yang lebih kontekstual dan memiliki konten informasi serta tampilan visual yang representatif dan informatif untuk melengkapi yang sudah ada. Metode penelitian yang dilakukan adalah metode kualitatif, dalam proses pengumpulan data dan analisis, kemudian akan dilakukan wawancara pada pihak yang berkepentingan dan observasi lapangan. Analisis perbandingan juga akan digunakan dalam menganalisis data-data visual yang ada. Hasil penelitian akan digunakan sebagai dasar merancang buku yang lebih kontektual, yakni akan menjelaskan mengenai potensi tiga pariwisata Kabupaten Maros, yaitu RammangRammang, Leang-Leang, dan Taman Nasional Bantimurung melalui tampilan fotografi disertai muatan teks informasi yang menjelaskan mengenai keindahan, keunikan, serta nilai sejarah yang terkandung di dalamnya. Diharapkan perancangan buku fotografi wisata ini dapat berperan besar dalam membantu promosi Program Wisata Pendidikan milik Dinas Kebudayaan dan Pariwisata Kabupaten Maros.
\end{abstract}

Kata kunci: Buku, Fotografi, Promosi, Pariwisata Maros, Karst.

Abstract: Maros District on South Sulawesi Province has many interesting natural sites with historical values. Based on that potency, the Department of Culture and Tourism Maros created a program called 'Educational Tour'. This program provides recreation activities as well as education about the natural and historical knowledge contained in the three tourist destinations, namely Rammang-Rammang, Leang-Leang, and Bantimurung. The Department has already done some form of promotion about the program, one of them is photo-book. However, based on the explanation of Head of Creative Economy the scope of the book is too broad and the information explained about the Maros tourism is not complete. The design's method used by the author is a qualitative method. In the process of data collection and analysis, the writer distributes questionnaires, interviews, and observations. The author uses comparative analysis to analyze the data. Based on the

${ }^{1}$ Mahasiswa Program Studi DKV Telkom University, email: parhangmanusiakeripik@gmail.com

2Pengajar Program Studi DKV Telkom University, email: vidiyan@gmail.com 
explanation above, it needs photo-book design with informative content and attractive in terms of design. This book will explain the three potentials tourism destination of Maros, which are Rammang-Rammang, Leang-Leang, and the National Park Bantimurung through photographic display with informative text, describing the beauty, uniqueness and historical value contained. The author hopes the design of this tourism photo-book can be an instrument in helping the promotion of 'Educational Tour' program that belongs to the Department of Culture and Tourism Maros.

Keywords: Book, Photography, Promotional, Maros Tourism, Karst.

\section{PENDAHULUAN}

Maros merupakan salah satu kabupaten yang terletak di Provinsi Sulawesi Selatan, Indonesia. Ibu kota kabupaten ini terletak di Kota Maros. Tidak hanya keunikan dan keragaman obyek serta khasanah seni dan budaya, Kabupaten Maros juga terkenal karena memiliki ragam panorama alam serta kekayaan flora dan fauna, diantaranya seperti wisata gua, hutan, satwa liar, air terjun, pemandangan puncak bukit kapur, dan sebagainya. Hal ini menjadikan Kabupaten Maros memiliki daya tarik wisata yang khas serta berpotensi besar untuk dilakukannya pengembangan pariwisata.

Selaku tugasnya dalam mewujudkan perkembangan pariwisata Kabupaten Maros, Dinas Kebudayaan dan Pariwisata Kabupaten Maros telah meluncurkan berbagai macam program, salah satunya bernama Wisata Pendidikan. Program wisata pendidikan yang menargetkan kalangan umum dari SD hingga mahasiswa ini diusulkan pada tahun 2015 lalu, didalamnya berisi kegiatan rekreasi alam sekaligus edukasi pendidikan mengenai pengetahuan alam dan sejarah yang terdapat pada tiga destinasi wisata, yaitu Rammang-Rammang, Leang-Leang, dan Taman Nasional Bantimurung. Alasan penentuan tiga wisata tersebut selain karena lokasi cukup berdekatan, ketiga tempat ini memiliki keindahan khas berupa bebatuan karst (bentuk formasi pegunungan yang diakibatkan dengan adanya kumpulan bebatuan kapur) yang menggunung dan memiliki nilai sejarah tinggi serta jarang ditemui di daerah lain. 
Lokasi pertama adalah Bantimurung, merupakan salah satu tujuan wisata unggulan yang di dalamnya terdapat penangkaran kupu-kupu, goa prasejarah, cagar alam dan yang paling terkenal adalah air terjunnya yang mengalir di antara tebing-tebing karst. Berdasarkan data yang diperoleh dari situs resmi yaitu tnbabul.org, kawasan karst yang terdapat di Bantimurung ini dinobatkan kawasan karst terluas kedua di dunia setelah China Selatan dan sempat diusulkan sebagai World Heritage atau warisan dunia sekitar tahun 2000 lalu.

Lokasi yang kedua, yakni Taman Prasejarah Leang-Leang terletak pada deretan bukit kapur/ karst yang curam. Menurut para arkeolog, beberapa gua yang terdapat dikawasan tersebut pernah dihuni manusia sekitar 3000-8000 tahun sebelum masehi, hal ini dapat terlihat dari lukisan prasejarah yang ada. Keunikan lain dikawasan ini adalah sungai yang berada tepat didepan Gua Leang-Leang, singkapan batu kapur yang tersebar di area persawahan penduduk dan pemandangan Puncak Bulusaraung dari atas gua.

Terakhir adalah Situs Prasejarah Rammang-Rammang, berupa sebuah tempat pada gugusan pegunungan karst. Salah satu keunikan dalam mengunjungi tempat ini adalah rangkaian perjalanan yang harus melewati Sungai Pute menggunakan jasa perahu yang disediakan. Tempat ini memiliki perpaduan bentang alam yang indah serta peninggalan gua prasejarah semakin menambah daya tarik wisata kawasan ini.

Pihak Dinas mengetahui bahwa masih banyak masyarakat di luar Pulau Sulawesi yang belum mengenal keunggulan wisata karst yang terdapat di Kabupaten Maros. Oleh sebab itu, mereka telah melakukan berbagai macam bentuk promosi, salah satunya melalui media buku. Buku tersebut seringkali digunakan untuk kebutuhan antar dinas seperti kegiatan studi banding dan lainnya. Di dalamnya berisi konten mengenai hal-hal yang berhubungan dengan Kabupaten Maros mulai dari segi budaya, wisata, sosial dan lain-lain. Namun menurut Bapak Samsir selaku Kepala Bidang Ekonomi Kreatif, lingkup pembahasan 
dari buku ini terlalu luas dan paparan informasi mengenai wisata Karst Maros tidak lengkap. Buku juga dinilai memiliki beberapa masalah dari sisi estetika desain dan konten. Diantaranya seperti cover buku yang kurang menggambarkan lokasi wisata, tata layout yang kurang rapi, pemilihan warna kurang tepat, juga beberapa ilustrasi foto yang tidak berhasil menggambarkan tempat wisata dengan menarik. Hal ini tentu mengganggu kegiatan promosi yang dilakukan oleh Dinas Pariwisata, terutama ketika buku ini digunakan sebagai contoh representasi visual Kabupaten Maros. Buku dinilai tidak berhasil memvisualisasikan dan menginformasikan wisata Kabupaten Maros dengan cukup menarik yang tentunya hal ini membuat masyarakat tidak berantusias untuk berkunjung. Oleh sebab itu, Dinas membutuhkan sebuah buku yang khusus membahas tiga objek wisata karst Wisata Pendidikan dengan informasi yang lebih spesifik dan detail, sebagai media untuk mempromosikan wisata Karst Kabupaten Maros kepada masyarakat. Berdasarkan uraian tersebut maka dapat ditarik rumusan masalah berupa pertanyaan bagaimana merancang sebuah buku yang representative, sehingga dapat membantu mempromosikan obyek-obyek wisata karst di Kabupaten Maros.

\section{KAJIAN TEORI}

Berdasarkan Ensiklopedia Indonesia, buku adalah sebuah benda yang di dalamnya mencakup tulisan dan gambar yang ditulis dan dilukiskan di atas segala macam lembaran papyrus, lontar, perkamen dan kertas dengan segala bentuknya, berupa gulungan, dilubangi dan diikat atau dijilid muka belakangnya dengan kulit, kain, karton atau kayu. Fungsinya yaitu untuk menyampaikan informasi, berupa cerita, pengetahuan, laporan dan lain-lain. Buku dapat menampung banyak informasi, tergantung dengan jumlah halamannya. (Rustan, 2009)

Berdasarkan penjelasan Enche Tjin \& Erwin Mulyadi (2014 : 66), Fotografi (photography) adalah gabungan dari dua kata dalam bahasa Yunani yaitu Photos (cahaya) dan Graphos (gambar) yang memiliki arti menghasilkan gambar dengan 
merekam cahaya. Sehingga pada prakteknya, diperlukan komponen peka cahaya yang sekarang dikenal dengan istilah film atau sensor. Sedangkan foto merupakan istilah untuk menyebut gambar yang diambil menggunakan kamera. Fotografi digunakan dalam berbagai kebutuhan, salah satunya adalah industri periklanan. Menurut Surianto Rustan dalam buku "Layout Dasar dan Penerapannya" (2009), kekuatan terbesar dari fotografi pada media periklanan khususnya adalah kredibilitasnya atau kemampuannya untuk memberi kesan 'dapat dipercaya'.

Mengenai pariwista, Pendit (2002) menjelaskan bahwa pariwisata merupakan bagian dari kehidupan manusia yang menyangkut kegiatan sosial dan ekonomi. Indonesia sebagai negara yang sedang berkembang, berusaha untuk membangun industri pariwisata sebagai salah satu langkah untuk mencapai neraca perdagangan luar negeri yang berimbang. Melalui hal ini, kita berharap bertambahnya pemasukan devisa negara. Sedangkan orang yang mengunjungi pariwisata tersebut disebut wisatawan. Dari penjelasan Soekadijo (2000 : 2) wisatawan adalah pengunjung yang mengunjungi suatu daerah berdasarkan motivasi untuk mengisi waktu senggang atau untuk bersenang-senang, berlibur, untuk alasan kesehatan, studi, keluarga, maupun bisnis.

\section{METODE PENELITIAN}

Observasi dilakukan pada tiga lokasi wisata karst yang berlokasi di Kabupaten Maros, Sulawesi Selatan, yaitu Rammang-Rammang, Leang-Leang, dan Taman Nasional Bantimurung. Tujuan observasi mencakup dokumentasi wahana wisata, informasi pengetahuan dan sejarah, deskripsi wilayah dan kecenderungan akan aktivitas pengunjung.

Data yang lebih mendalam didapatkan dengan mewawancarai Kepala Dinas Kebudayaan dan Pariwisata Kabupaten Maros dan Kepala Bidang Ekonomi Kreatif guna mendapatkan informasi mengenai program Wisata Pendidikan secara 
merinci, serta informasi tambahan yang dimiliki oleh dinas mengenai tiga wisata karst Maros.

Untuk data sekunder berupa studi pustaka, pengumpulan data dilakukan melalui tulisan yang berhubungan dengan pembahasan, dimulai dari buku, website resmi, artikel, jurnal, dan lain-lain.

\section{DATA KHALAYAK SASARAN}

Khalayak sasaran buku ini adalah pria dan wanita berusia 20 sampai 30 tahun dengan status ekonomi A dan B, utamanya berdomisili di Indonesia dan memiliki antusiasme tinggi terhadap keindahan alam Indonesia, serta menyukai aktivitas travelling ataupun menjelajah.

Hingga saat ini pengunjung wisata yang datang ke Kabupaten Maros sebagian besar berasal dari luar daerah Kabupaten Maros, dan sebagian lagi berasal dari luar pulau Sulawesi bahkan dari luar Indonesia. Kegiatan yang dilakukan para wisatawan antara lain adalah foto-foto, menikmati pemandangan, dan menikmati fasilitas petualangan yang disajikan pada masing-masing tempat wisata.

\section{HASIL DAN DISKUSI}

Untuk menentukan ide besar dari konsep perancangan buku, dilakukan analisis pada buku-buku fotografi pariwisata lain, yang memiliki ciri khas masingmasing seperti penerapan olah warna pada foto, penggayaan bahasa pada teks, pengaturan layout yang variatif sampai yang konsisten, ataupun tata letak foto yang dapat menimbulkan kesan berbeda-beda. Perancangan konsep dilakukan berdasarkan isi konten pada buku dengan mempertimbangkan khalayak yang akan disasar oleh buku itu sendiri. 
Tabel 1. Perbandingan Buku Fotografi Pariwisata

\begin{tabular}{|c|c|c|c|}
\hline Judul Buku & Verge On Voyage & Nusa Penjaga Indonesia & Kepulauan Anambas \\
\hline Cover & 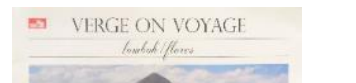 & & \\
\hline Penyusun & Ruben Kristianto & $\begin{array}{l}\text { Batubara, } \\
\text { Rido Miduk Sugandi }\end{array}$ & $\begin{array}{l}\text { Tim Kementrian } \\
\text { Kelautan Dan Perikanan }\end{array}$ \\
\hline $\begin{array}{l}\text { Dimensi } \\
\text { Produk }\end{array}$ & $\begin{array}{l}20 \times 20 \mathrm{~cm} \\
\text { (square oriented) }\end{array}$ & $\begin{array}{l}23 \times 30 \mathrm{~cm} \\
\text { (landscape oriented) }\end{array}$ & $\begin{array}{l}15 \times 23 \mathrm{~cm} \\
\text { (portrait oriented) }\end{array}$ \\
\hline $\begin{array}{l}\text { Jumlah } \\
\text { Halaman }\end{array}$ & 120 hal. & 288 hal. & 150 hal. \\
\hline Tipografi & $\begin{array}{l}\text { Tipografi yang digunakan } \\
\text { pada judul buku sesuai } \\
\text { dengan kolaborasi foto } \\
\text { dan frame. Sedangkan } \\
\text { penentuan font pada } \\
\text { headline dan beberapa } \\
\text { teks lainnya seringkali } \\
\text { berubah-ubah sehingga } \\
\text { terkesan tidak konsisten. } \\
\text { Untuk bodytext, } \\
\text { ukurannya sedikit kecil } \\
\text { sehingga menciptakan } \\
\text { nuansa white space pada } \\
\text { halaman secara umum, } \\
\text { namun masih dapat } \\
\text { dibaca dengan baik. }\end{array}$ & $\begin{array}{l}\text { Tipografi sudah tampil baik } \\
\text { dan ukuran yang digunakan } \\
\text { berhasil memberi daya tarik } \\
\text { pada cover. Penerapan } \\
\text { ukuran pada headline juga } \\
\text { tampil besar namun sesuai } \\
\text { dengan ukuran buku yang } \\
\text { agak besar, sehingga } \\
\text { headline maupun bodytext } \\
\text { tetap nyaman dibaca. }\end{array}$ & $\begin{array}{l}\text { Tipografi yang digunakan } \\
\text { pada sampul sudah } \\
\text { cukup bagus, namun } \\
\text { peletakannya terlihat } \\
\text { kurang nyaman karena } \\
\text { seperti berdempetean } \\
\text { dengan objek penyelam } \\
\text { di foto. Ukuran headline } \\
\text { dan upaya highlightnya } \\
\text { cukup baik dan tidak } \\
\text { ada masalah, sedangkan } \\
\text { ukuran bodytext tampil } \\
\text { sedikit kecil, namun } \\
\text { masih dapat dibaca } \\
\text { dengan baik. }\end{array}$ \\
\hline Layout Foto & $\begin{array}{l}\text { Layout tidak konsisten, } \\
\text { tata letaknya tidak } \\
\text { memiliki sistem yang } \\
\text { teratur, pengaturan } \\
\text { ukuran foto tidak } \\
\text { seimbang, ada yang } \\
\text { tampil terlalu kecil. }\end{array}$ & $\begin{array}{l}\text { Variasi layout cukup minim } \\
\text { dengan tata letak yang } \\
\text { seringkali tampil berulang } \\
\text { pada beberapa halaman. } \\
\text { Layout sudahtampil dengan } \\
\text { baik dan minimnya variasi } \\
\text { tata letak membuat layout } \\
\text { buku tampil konsisten secara } \\
\text { keseluruhan sehingga nyaman } \\
\text { untuk dibaca. }\end{array}$ & $\begin{array}{l}\text { Layout cukup bervariasi } \\
\text { namun tetap memiliki } \\
\text { pengukuran yang baik } \\
\text { dan seimbang sehingga } \\
\text { bisa tampil lebih menarik } \\
\text { dari buku lainnya. }\end{array}$ \\
\hline Layout Teks & $\begin{array}{l}\text { Tata letak berubah-ubah, } \\
\text { sebagian tampak terlalu } \\
\text { mepet dengan tepi } \\
\text { kertas, pengaturan } \\
\text { alignment yang kadang } \\
\text { berubah dan kurang } \\
\text { tepat. Walau begitu, }\end{array}$ & $\begin{array}{l}\text { Layout sudah baik dalam } \\
\text { menampilkan informasi dalam } \\
\text { buku walau memang minim } \\
\text { variasi, namun hal ini justru } \\
\text { menjadikan informasi nyaman } \\
\text { dibaca karena letaknya yang } \\
\text { tidak berubah banyak. }\end{array}$ & $\begin{array}{l}\text { Layout teks bervariasi } \\
\text { namun ditata dengan } \\
\text { baik sehingga tetap } \\
\text { mudah dan nyaman } \\
\text { dibaca. Letaknya pun } \\
\text { tidak menganggu ilustrasi } \\
\text { foto. }\end{array}$ \\
\hline
\end{tabular}


secara garis besar

informasinya masih

cukup nyaman dibaca.

\begin{tabular}{|c|c|c|c|}
\hline Fotografi & $\begin{array}{l}\text { Foto tajam, rapi, dan } \\
\text { menarik karena memiliki } \\
\text { ciri khas pada konsep } \\
\text { bukunya, dimana penulis } \\
\text { buku difoto dari belakang } \\
\text { dengan tampilan } \\
\text { pemandangan lokasi } \\
\text { rekreasi yang luas di } \\
\text { hadapannya. Pada } \\
\text { beberapa foto dari segi } \\
\text { warnanya diseting tidak } \\
\text { terlalu vibran, sehingga } \\
\text { menciptakan kesan foto } \\
\text { yang cukup calm dan } \\
\text { menenangkan mata. }\end{array}$ & $\begin{array}{l}\text { Foto tajam, komposisi cukup } \\
\text { baik, memiliki warna yang } \\
\text { vibran, menarik dan nikmat } \\
\text { dipandang mata. Penerapan } \\
\text { pengaturan warna melalui } \\
\text { olah digital yang disesuaikan } \\
\text { pada objek-objek foto } \\
\text { membuat setiap halaman } \\
\text { menyajikan foto yang } \\
\text { bervariasi dan berwarna, } \\
\text { sehingga berhasil } \\
\text { menghindarkan kesan } \\
\text { menjenuhkan. }\end{array}$ & $\begin{array}{l}\text { Foto tajam, komposisi } \\
\text { cukup baik dan berhasil } \\
\text { menampilkan objek- } \\
\text { objek yang menarik. } \\
\text { Dari segi warna, } \\
\text { tampaknya foto tidak } \\
\text { diolah digital cukup jauh } \\
\text { sehingga warna-warna } \\
\text { pada foto tampak } \\
\text { original dengan warna } \\
\text { yang asli yang kita lihat. } \\
\text { Hal ini tidak mengganggu } \\
\text { kualitas foto yang sudah } \\
\text { tampil dengan baik. }\end{array}$ \\
\hline Warna & $\begin{array}{l}\text { Menggunakan warna } \\
\text { putih sebagai latar } \\
\text { belakang halaman, teks } \\
\text { menggunakan warna } \\
\text { hitam, serta beberapa } \\
\text { pattern berwarna abu- } \\
\text { abu, hitam, bahkan pink } \\
\text { untuk keperluan } \\
\text { highlight pada beberapa } \\
\text { headline. Tampak tidak } \\
\text { konsisten karena } \\
\text { penerapannya tidak } \\
\text { sistematis. }\end{array}$ & $\begin{array}{l}\text { Menggunakan warna putih } \\
\text { sebagai latar belakang } \\
\text { halaman, headline } \\
\text { menggunakan warna biru } \\
\text { muda, bodytext } \\
\text { menggunakan warna hitam, } \\
\text { serta pattern pada beberapa } \\
\text { halaman menggunakan } \\
\text { warna biru muda. Secara } \\
\text { keseluruhan, penggunaan } \\
\text { kombinasi warna sudah } \\
\text { cukup baik dan nyaman } \\
\text { dibaca, kecuali pada pattern. } \\
\text { Beberapa teks yang } \\
\text { diterapkan diatas pattern } \\
\text { bermasalah dengan } \\
\text { readibility kena pattern } \\
\text { berwarna biru muda } \\
\text { sedangkan teks berwarna } \\
\text { putih dan berukuran tipis. }\end{array}$ & $\begin{array}{l}\text { Menggunakan warna } \\
\text { putih sebagai latar } \\
\text { halaman, teks berwarna } \\
\text { hitam, warna merah } \\
\text { pada highlight beberapa } \\
\text { teks mengenai objek } \\
\text { pembahasan, dan warna } \\
\text { hijau pada highlight } \\
\text { nomor halaman. Warna } \\
\text { merah dan hijau } \\
\text { berukuran kecil sehinga } \\
\text { tidak mengganggu teks } \\
\text { dan foto. Secara } \\
\text { keseluruhan, porsi warna } \\
\text { diberikancukup pas pada } \\
\text { konten sehingga muatan } \\
\text { informasi dan fotografi } \\
\text { tetap tampil sebagai } \\
\text { focal point yang utama } \\
\text { dan paling menarik. }\end{array}$ \\
\hline
\end{tabular}

Dari hasil pengamatan pada tiga contoh buku fotografi di atas, yang memiliki keunggulan terbanyak secara aspek desain adalah buku Nusa Penjaga, sehingga akan dijadikan acuan sebagai perancangan buku yang baru. Beberapa aspek diantaranya adalah tipografi, layout, warna dan fotografi. Pada tipografi, penerapan ukuran huruf pada headline dan bodytext sudah cukup seimbang juga pengaturan warna dan tata letaknya tampil kontras dengan background text, sehingga informasi mudah dan nyaman dibaca. 
Sedangkan untuk layout, variasinya minim dengan tata letak yang seringkali tampil berulang pada beberapa halaman, hal ini membuat layout buku tampil konsisten secara keseluruhan sehingga nyaman untuk dibaca. Dari segi fotografi, beberapa foto melewati proses editing dengan peningkatan vibrance yang sesuai untuk menampilkan kekayaan warna alam pada foto. Tentunya, pengaturan warna melalui olah digital disesuaikan pada objek-objek foto, sehingga setiap halaman dapat menyajikan foto yang bervariasi dan berwarna.

Terakhir aspek warna, yakni menggunakan warna dasar putih sebagai latar belakang dan hitam pada bodytext agar informasi tampil kontras dan mudah dibaca. Kemudian untuk headline dan nomor halaman menggunakan warna yang telah dipilih dari penetapan identitas visual. Penggunaan warna yang berbeda dan kontras akan membantu pembaca untuk menentukan focal point pada isi buku, juga dapat menampilkan visual identity pada buku sebagai nilai tambah.

\section{KONSEP PERANCANGAN}

\section{Konsep Pesan}

Konsep pesan pada buku yang ingin dibangun adalah mengajak masyarakat untuk mengenal, mengunjungi dan menjelajahi keunikan tiga wisata karst yang terdapat pada Kabupaten Maros di Sulawesi Selatan, serta menginformasikan nilai-nilai sejarah dan ilmu pengetahuan yang terdapat di. Dari itu semua, disusunlah suatu kalimat rangkuman yang mencakup konsep ini, yaitu "Menapaki 3 Karst di Maros", frase ini menjelaskan tentang proses menjejaki dan menyelidiki keunggulan serta keunikan yang terdapat pada tempat wisata ini, yang notabene berhubungan dengan daerah berbatu kapur.

\section{Konsep Kreatif}

Konsep kreatif menggunakan ilustrasi visual berupa fotografi. Pada dasarnya, ilustrasi berfungsi untuk menjelaskan suatu hal dan fotografi merupakan salah satu ilustrasi visual yang digunakan untuk memberikan gambaran secara 
jujur dan berdasarkan fakta yang ada, mengenai narasi atau tulisan yang sedang disampaikan.

\section{Konsep Media}

Konsep media menggunakan buku dengan muatan ilustrasi foto yang populernya disebut sebagai buku fotografi atau photobook. Disamping kekurangannya, photobook masih memiliki keunggulan yang belum tergantikan dibandingkan dengan media digital lain, mulai dari pengalaman interaksi ketika menggunakannya, aspek kenyamanan, serta kepraktisannya dari segi mengakses karena tidak memerlukan media elektronik.

Buku yang dirancang berukuran $12 \times 9$ inchi / $30.48 \times 22.86 \mathrm{~cm}$ (orientasi landscape), hard-cover dengan isi berbahan tik paper. Dari segi konten, buku berisi foto dokumentasi tiga wisata karst yaitu Taman Wisata Bantimurung, Taman PraSejarah Leang-Leang dan Tebing Karst Rammang-Rammang disertai deskripsi mengenai tempat wisata, spot-spot menarik yang dimilikinya, serta informasi sejarah dan ilmu pengetahuan yang terdapat di dalamnya.

\section{Konsep Visual}

Berdasarkan rancangan media berupa buku fotografi wisata, konsep visual akan memuat berbagai unsur visual yang berhubungan dengan buku, seperti font, ilustrasi, warna, dan layout. Font "Bicycle" digunakan pada penulisan judul buku, headline dan sub-headline. Font ini membawa nuansa fun pada buku dengan ornamen dinamisnya namun tetap tampil profesional karena sifat tegak pada hurufnya yang elegan. Sedangkan font "Titillium Wb" digunakan pada bodytext. Termasuk kategori font sans-serif sehingga informasi pada buku bisa tampil dengan nuansa modern, elegan namun tetap formal. 


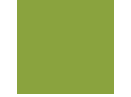
H: 76
S: 46
$\mathrm{L}: 44$
H: 49 S: 32
$L: 43$

Gambar 1. Skema warna utama

(Sumber: Fachriansyah \& Rahman, 2018)

Pemilihan warna dipilih berdasarkan citra suasana alam, yaitu warna hijau dan tanah yang mewakili warna daun, tumbuh-tumbuhan, pepohonan dan tanah. Perancangan ilustrasi berupa foto bergenre Landscape Photography. Genre fotografi ini mencakup pemotretan objek alam seperti, gunung, sungai, bukit, laut, dan sebagainya. Kadangkala, foto disisipi dengan objek manusia guna menguatkan gambaran mengenai luasnya tempat pada foto.
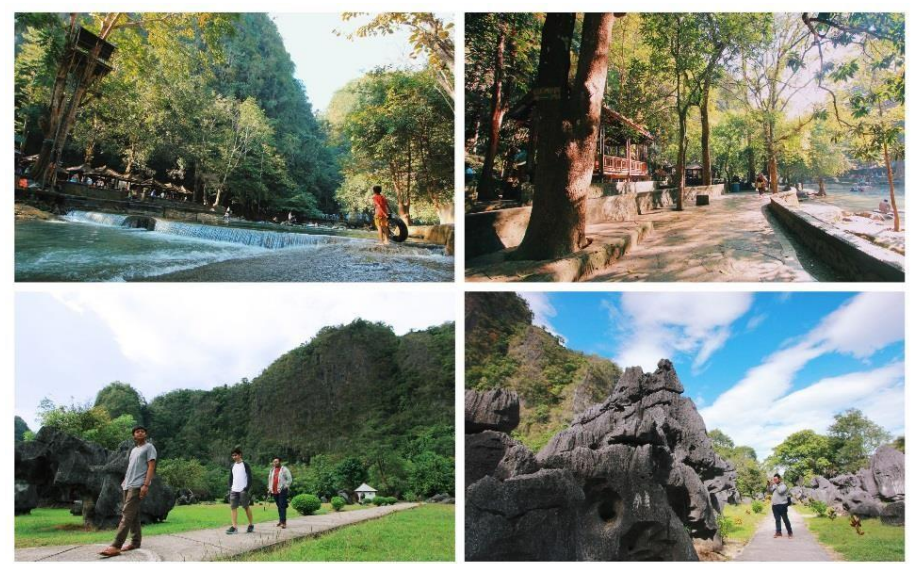

Gambar 2. Wisata Maros

(Sumber: Fachriansyah \& Rahman, 2018)

Buku dirancang dengan menggunakaan penggayaan layout yang disebut Technical Design, model desain dengan seting ruang kosong yang tersedia cukup banyak untuk mengarahkan pembaca untuk fokus pada teks dan visual di dalamnya, serta pengaturan kolom yang tidak lebar dan tidak memuat teks yang terlalu banyak. 

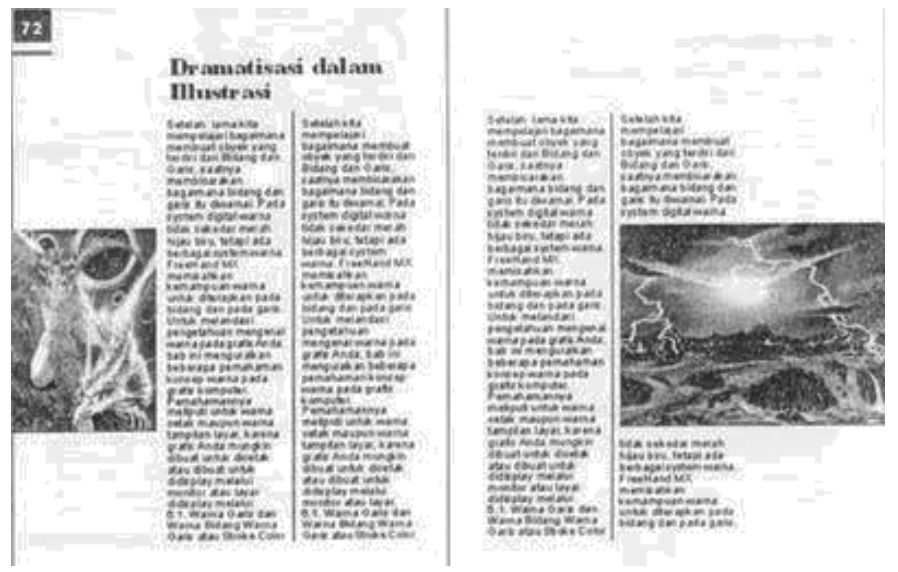

Gambar 3. Technical Design.

(Sumber: "Layout" Pranti Sayek )

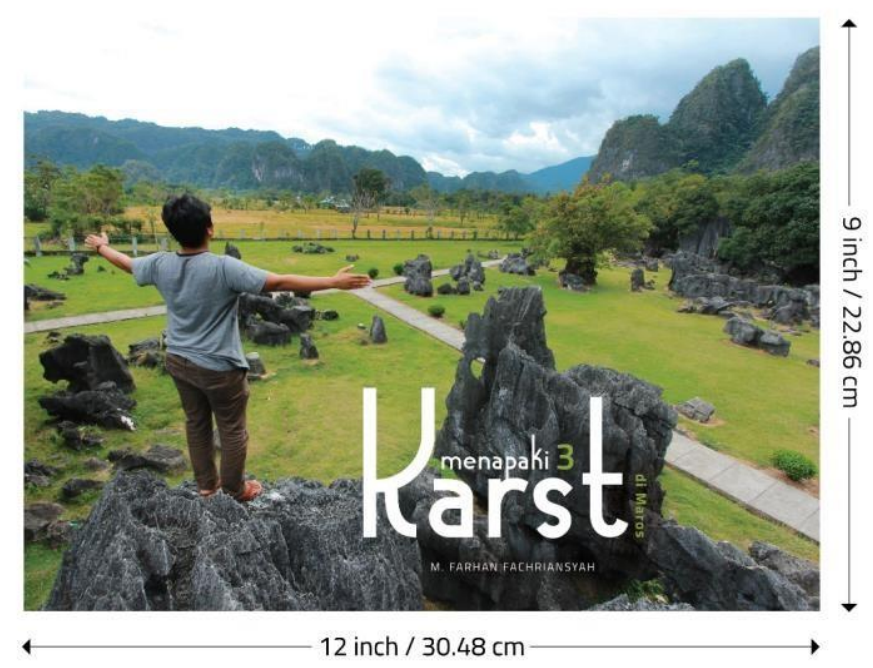

Gambar 4. Ukuran Buku

(Sumber: Fachriansyah \& Rahman, 2018) 


\section{HASIL PERANCANGAN}
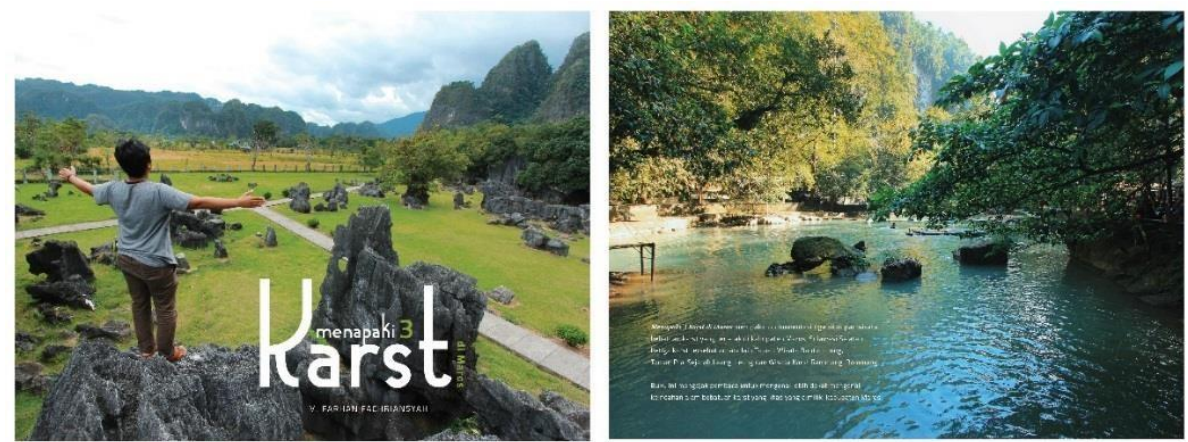

Gambar 5. Cover Depan dan Belakang

(Sumber: Fachriansyah \& Rahman, 2018)
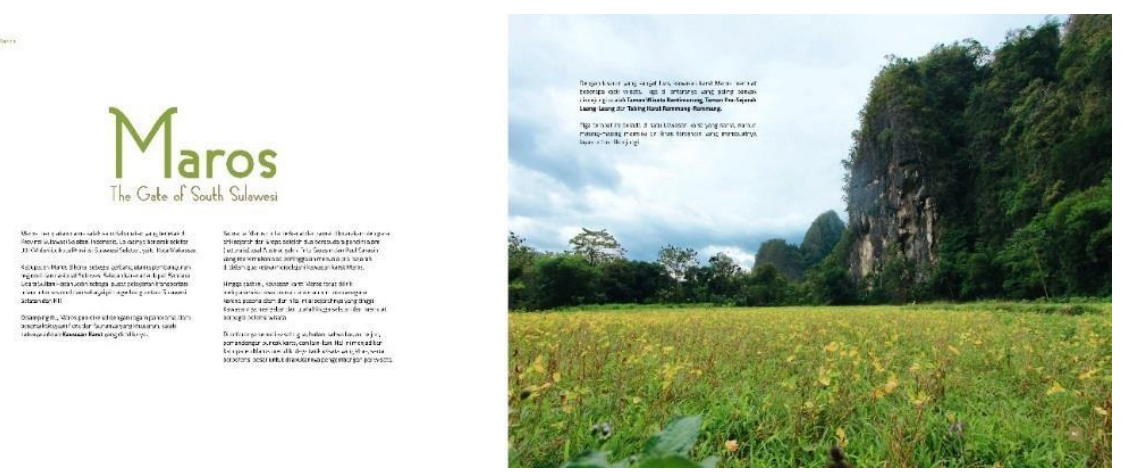

Gambar 6. Isi Buku 1

(Sumber: Fachriansyah \& Rahman, 2018)
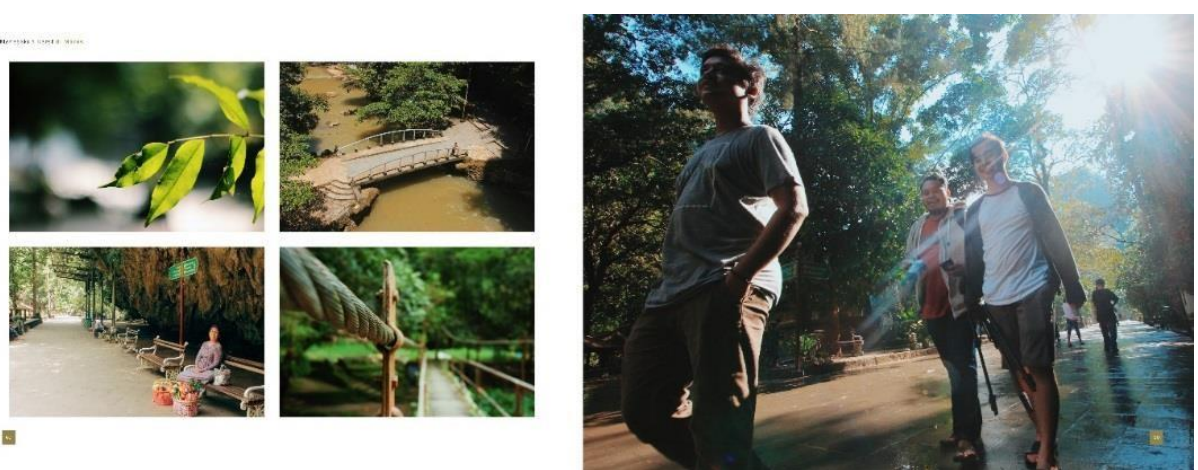

Gambar 7. Isi Buku 2

(Sumber: Fachriansyah \& Rahman, 2018) 


\section{KESIMPULAN}

Berdasarkan hasil penelitian yang dilakukan, maka ada beberapa kesimpulan yang dapat diambil, pertama dapat dinyatakan bahwa Kabupaten Maros membutuhkan sebuah buku yang representatif untuk membantu mempromosikan wisata Karst di Kabupaten Maros. Kemudian dalam prosesnya, perancangan buku fotografi dengan berbagi tekniknya dapat diupayakan untuk bisa menghasilkan sebuah media yang layak secara visual dan dapat digunakan untuk mempromosikan tempat-tempat wisata yang potensial di Kabupaten Maros. Kekuatan buku fotografi yang menggambarkan sebuah tempat dengan jujur bisa menjadi kekuatan tersendiri sebagai media berpromosi. Lalu yang ketiga, dengan adanya buku fotografi ini, diharapkan bisa membantu Pemerintah Kabupaten Maros untuk menginformasikan kepada pihak-pihak terkait tentang keadaan dan potensi wisata yang ada untuk bisa dijelajahi oleh masyarakat luas.

\section{DAFTAR PUSTAKA}

Pambudi, Teguh. 2015. Panduan Wisata Jawa Tengah. Semarang: Dinas Kebudayaan Dan Pariwisata Provinsi Jawa Tengah.

Pendit, Nyoman S. 2002. Ilmu Pariwisata Sebuah Pengantar Perdana. Jakarta: Pradya Paramita

Rustan, Surianto. 2009. Layout Dasar dan Penerapannya. Jakarta: Gramedia Pustaka Utama.

Safanayong, Yongky. 2006. Desain Komunikasi Visual Terpadu. Jakarta: Arte Intermedia.

Soekadijo, R. G. 2000. Anatomi Pariwisata: Memahami Pariwisata Sebagai Systemic Linkage. Jakarta: Gramedia Pustaka Utama.

Tjin, Enche dan Mulyadi, Erwin. 2014. Kamus Fotografi. Jakarta: Elex Media Komputindo

Umbara, Denny P. 2015. Perancangan Buku Fotografi Wisata Alam Kabupaten Kaur. Skripsi Universitas Telkom. 